\title{
Effect of various inlet geometries on swirling flow in can combustor
}

\author{
W. Treedet and R. Suntivarakorn* \\ Department of Mechanical Engineering, Faculty of Engineering, Khon Kaen University \\ 123 Mitraparp Road, Khon Kaen, Thailand, 40002 \\ *Email: ratchaphon@kku.ac.th \\ Phone: +6643202845; Fax: +6643202849
}

\begin{abstract}
This paper presents the effects of various inlet geometries on swirling flow and a study of the flow behavior of air in the can combustor using a CFD model. In this work, the standard k- $\varepsilon$ turbulence model was used. Furthermore, for this study, the can combustor had an inner diameter, outer diameter, and length of $250 \mathrm{~mm}, 290 \mathrm{~mm}$, and $406 \mathrm{~mm}$, respectively. An annular swirler was used in order to generate a re-circulating velocity in the chamber of combustor. Various inlet geometries were designed and experiments were conducted to study the effects of these designs on the swirling flow inside the combustor. To understand the flow behavior, the snout angles varied at $30^{\circ}, 45^{\circ}$, and $60^{\circ}$ angles, and the hub to tip ratio of the vane swirler varied at 0.33 and 0.67 . The results showed that the following had an influence upon the Central Re-circulating Zone (CRZ) and Pressure Loss factor (PLF) in a combustor: 1) the snout angle, 2) the hub to tip ratio of the annular swirler, and 3 ) the auxiliary primary holes. It was also found that the optimum design of this can combustor had a snout angle of 30 degrees and a hub to tip ratio of the swirler of 0.33 . In order to create the optimum design for a large CRZ and lowest PLF, it was found that auxiliary primary holes should be also used.
\end{abstract}

Keywords: Can combustor; Swirling Flow; Flow behavior; Central Re-circulating Zone.

\section{INTRODUCTION}

A can combustor (or tubular combustor) is one type of continuous burning combustor used in gas turbines, ram jets, or scramjet engines. The purpose of the combustor in a gas turbine is to add energy, which can be used, in the system of a power station. In addition, the can combustor can be used in a drying system or heat generator, etc. The suitability of any continuous combustor is based upon its size, thermal load, the flue gas temperatures, and operating conditions, etc $[1,2]$. However, the following requirements for accomplishing the design must be considered: 1) the complete combustion between fuel and air, 2) a drop in pressure in the combustor, 3) flame retention inside the combustor, 4) a uniformity of the exit temperature from combustor to prevent damage or destruction of devices by thermal cracking, and 5) finally, an avoidance of environmental pollution [3].

Normally, the flow behavior of air in a continuous combustor has the characteristic of a toroidal reversal flow (or re-circulates) into a portion where it can generate a Central Recirculation Zone (CRZ). The CRZ is helpful in mixing the fuel and air in order to increase the combustion time which generates complete combustion [4]. The robustness of CRZ is indicated by the swirl number $\left(S_{n}\right)$ in the combustor [5]. A swirl number is expressed in Eq. (1), 


$$
S_{n}=\frac{\int_{0}^{R} \rho U W r^{2} d r}{R \int_{0}^{R} \rho U^{2} r d r}
$$

in which $U, W$ and $R$ are the axial velocity, tangential velocity, and swirler radius, respectively. This number is the ratio of the axial flux of angular momentum to the axial flux of the axial momentum. Generally, the swirl number is designed to be greater than 0.6 to provide stabilization for the burner [6].

Over the last decades, many researchers have indicated the following: 1) the geometry of the combustor, 2) the geometry of the diffuser, 3) the geometry of the swirler, 4) the diameters and arrangements of the primary, secondary and dilute holes of the liners, and 5) the characteristics of a liner and outer case which can greatly influence the CRZ, Pressure Loss Factor (PLF), and the combustion efficiency [6-8]. However, the methodology involved with designing a high efficiency combustor must utilize complicated theories, such as theories of fluid mechanics, combustion, and mechanical design. During the process of designing and testing each of the combustors, there will be a very high expenditure of cost and time, and mistakes are not allowed in this process. Therefore, presently Computational Fluid Dynamics (CFD) is one choice being used to design can combustors $[9,10]$.

Singh et al. has studied the flow characteristics of an annular gas turbine combustor by using CFD. The results of the study showed that allowing a fraction of air into the swirler, the primary holes, secondary holes, and into the dilute holes has influenced the creation of CRZ which has directly affected the combustion efficiency. The suitable volumes of air in the liner of the primary, secondary and dilute holes were found to be $22.51 \%, 22.93 \%$ and $54.56 \%$, respectively [11]. However, the volume of combustion chamber did not have an effect on creating CRZ because the air/fuel ratio was still constant [12]. In addition, the turbulence model in this work showed that the turbulence $\mathrm{k}-\varepsilon$ standard gave better results for combustor prediction than other turbulence models $[11,13,15,16,17]$. The turbulence model from a study by Singh et al. was similar to research done by Green and Whitelaw [18], Lilley [19], Gupta et al. [20] and Sloan et al. [21]. In contrast, the results of Khandelwal et al. [22] and Vondal and Hajek [23], it has been indicated that the k- $\varepsilon$ realizable turbulence (developed by Shih et al. [24]) model is more precise in calculating the swirling flow problem than the $\mathrm{k}-\varepsilon$ STD, k- $\varepsilon$ RNG, k- $\omega$ SST, and the RSM models. However, a suitable turbulence model for CFD calculation was considered according to the inlet Reynolds number which has a direct effect upon the CRZ and turbulent intensity. The literature from Muthakumar and Balakrishnan [25] was found that the RMS turbulent model is suitable for a problem with an inlet Reynolds number of more than 125,000. Using the RMS turbulent model, the results of the axial velocity profile were more precise and stable than the results using the turbulence k- $\varepsilon$ STD model. In case the inlet Reynolds number is less than 125,000 , the turbulence k- $\varepsilon$ STD model has been found to be suitable for predicting the flow problem.

In addition, the air fraction had an effect on the CRZ, the modification of component of can combustor can also be an effect on the CRZ as well. Many researchers invented a method to improve the swirling number of can combustor by modification of swirler such as creation of rotation of the swirler between the air and the fuel [26], modification the vane angle of swirler [13,15,16,23,25], adjustment the number of blades of swirler [13,14,23,27] and modification the shape of blade swirlers [22,28]. However, Raj and Ganesan [29] studied the flow characteristics of air behind 
an annular vane swirler and the optimum design of the swirler geometry. From the results of the study, the optimum design of an annular vane swirler revealed that the number of blades, the vane angle in top view, and the angle of overlap from the axial direction were $8,45^{\circ}$, and $75^{\circ}$, respectively. This is consistent with the designs in many literatures $[13,14,16,23,27]$. Moreover, a modification or installation of devices into the swirler or combustor can create the CRZ such as invention a new concept for swirler design [5], creation a rotating vane of swirlers [30,31], increasing the air fraction in the hub of the swirler [15], increasing the stream of air around the blade swirler [17] and installation of a diffuser behind the swirler [32]. As a result, the acts of modifying the swirler, increasing the air around the swirler, or installing a diffuser could be considered as a way of making the devices in the combustor more effective, durable, and sustainable. In the combustion zone, the aerodynamics of combustion in part of the air fraction was directly affected by the size of combustor, which was a limitation of the combustor design in the gas turbine $[1,3]$.

This work presents the geometry of design for the combustion of can combustor by using CFD. Generally, the shape of combustor was similar to a rounded shape, which was difficult to construct. For this study, the shape of a can combustor was designed similarly to the diffuser shape to provide for ease of construction. The diffuser shape of the can combustor was directly related to the snout angle, and the effects of the snout angle were studied. An examination of CRZ creation with auxiliary primary holes was accomplished, and the effects of a different hub to tip ratios were also studied. There are only few research studies that have discussed the effects of the snout angle, the hub to tip ratios, and the auxiliary primary holes with respect to the generation of CRZ. The CFD model with the k- $\varepsilon$ STD turbulence model will be used in the combustion geometry design of the can combustor. The swirl number $\left(S_{n}\right)$ and pressure loss factor (PLF) were also utilized in determining a suitable design and in constructing the can combustor.

\section{CAN COMBUSTOR CONFIGURATIONSAND DESIGN}

A can combustor is comprised of a case, a diffuser, a liner, a snout, and a swirler, etc. The components of the can combustor are shown in Figure 1. A basic design for a can combustor must have the following qualifications: 1) be easy to build, 2) produce complete combustion, 3) have low emission levels, 4) produce a minimal loss of total pressure over a wide operating range, and 5) be durable [33]. In general, can combustors have a cylindrical design. When the combustion begins, a high pressure drop is created within the combustion zone. For this reason, the traditional can combustor must be designed with a diffuser shape that reduces air velocity [4]. The most important factor for accomplishing complete combustion is the creation of a swirling vortex inside the combustion chamber. The liner must divide the air into the combustion chamber in sufficient quantity, and furthermore, must reduce the temperature of the flue gas before it reaches the turbine blade. The liner can be divided into 3 zones which are primary zone, secondary zone and dilute zone [1,3].

In accomplishing the design of a can combustor, the following stoichiometric parameters must be used: 1) the fuel-air ratio, 2) the loading factor, 3) the combustion intensity, and 4) the residence time. The design methodology can be explained in literature of Walsh and Fletcher [34], which the design methodology was derived from basic theory for designing a can combustor in order to calculate inner and outer diameter, length of combustor, air fraction of primary, secondary and dilution zones of 
combustion and exhaust gas temperature. The air fraction was directly related to the numbers and diameters of holes in each combustion zone. These parameters require using air/fuel ratio, combustion temperature and flow rate of exhaust gas for geometry design. Therefore, the design methodology from Walsh \& Fletcher [34] cannot be used to predict or simulate the CRZ of flow inside a can combustor. The aim of this paper was to study only the flow characteristics in CRZ generation of air. As the air flow rate is higher than that of fuel gas, the effect of fuel gas flow and combustion characteristics on this design were not considered, and numerical calculations relating to the energy and flow turbulent model were not mentioned in this paper.
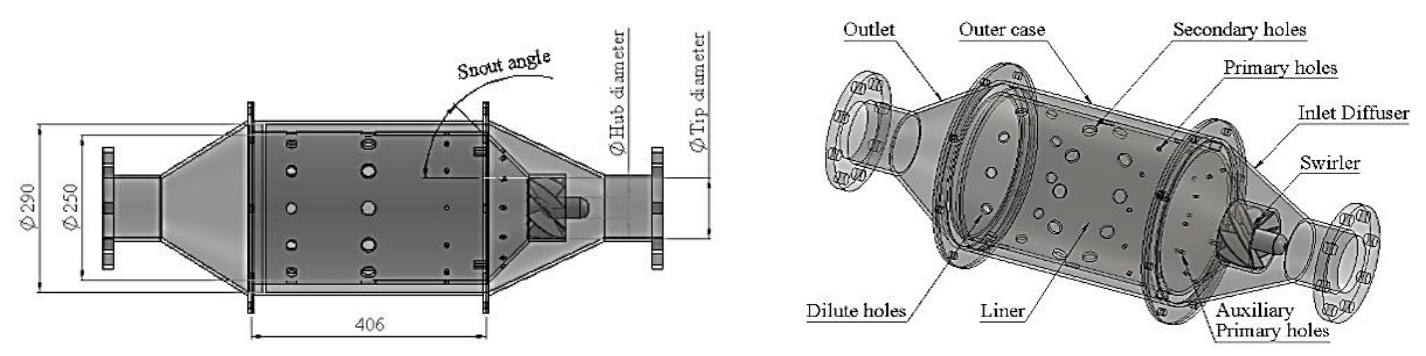

Figure 1. Dimension and components of the can combustor.

The 3D-modeling of a can combustor assumes the turbulent and the incompressible flow. The governing equations used for this work are mass conservation and the momentum equation. The standard $\mathrm{k}-\varepsilon$ turbulence model was used for this present study. The standard k- $\varepsilon$ turbulence model coefficients have the constant values following with literature of Yakhot et al. [35].

\section{DESIGN GEOMETRY AND COMPUTATIONAL DETAIL}

\section{Combustor design geometry}

The design of the can combustor, used in this study, has been conducted at atmospheric pressure, and Liquefied Petroleum Gas (LPG) was used as the fuel. The operational temperature was $300{ }^{\circ} \mathrm{K}$ and the constant mass flow rate of the air was $0.0157 \mathrm{~kg} / \mathrm{s}$. The design calculations are shown in Table 1. From Figure 1, the design of the can combustor consisted of an inlet diffuser, a liner, a swirler, and an outer case. The liner had a diameter of $250 \mathrm{~mm}$ and a length of $406 \mathrm{~mm}$. The holes of the liner were divided into 3 zones: 1) primary holes, 2) secondary holes and 3) dilute holes with each zone having a number of $12,12,12$ and a diameter of 6,24 and $18 \mathrm{~mm}$, respectively. The air fractions into the swirler in the primary, secondary, and dilute zones were $18.29 \%$, $9.15 \%, 40.24 \%$ and $32.32 \%$, respectively. The air fraction related to the flue gas temperature of the combustor (Table 2). The flue gas temperature of the combustor was increased due to the reduction of the air fraction in dilute zone. This research focused on a constant exit flue gas temperature of $1300{ }^{\circ} \mathrm{K}$. For this work, the swirler, that was utilized, was an annular swirler, as suggested by a study of Raj and Ganesan [29].

\section{Computational methodology}

The objective of this work was to study the following: 1) the influence of the Snout Angle (SA), 2) the hub to tip ratio (HTR) of the swirler, and 3) the influence of auxiliary primary holes (APH) on the liner on the CRZ and PLF. A study of the snout 
angles aimed at discovering the effect of air fraction between the liner and the outerliner, which directly affected the creation of CRZ.

Table 1. Design calculation of combustor.

\begin{tabular}{lcc}
\hline \multicolumn{1}{c}{ Description } & Value & Unit \\
\hline Stoichiometric F/A ratio & 0.0645 & - \\
Combustion loading & 1 & $\mathrm{~kg} / \mathrm{s} \mathrm{atm}{ }^{1.8} \mathrm{~m}^{3}$ \\
Combustion efficiency & 99.99 & $\%$ \\
Combustion intensity & 0.882 & $\mathrm{MW} / \mathrm{atm} \mathrm{m}$ \\
Combustion temperature & 2300 & ${ }^{\circ} \mathrm{K}$ \\
Residence time & 5.73 & $\mathrm{~ms}$ \\
Combustion volume & 0.0201 & $\mathrm{~m}^{3}$ \\
\hline
\end{tabular}

In order to provide for the easy construction of the can combustor, the standard angles of $30^{\circ}, 45^{\circ}$ and $60^{\circ}$ for the snouts angle (SA) were studied. In this study, the tip diameter was set at $105 \mathrm{~mm}$, while the hub diameter varied between 35 and $70 \mathrm{~mm}$, which caused the hub to tip ratios (HTR) of 0.33 and 0.67 , respectively. The study of the hub to tip ratio of the swirler aimed to uncover the effects of volumetric air flow rate and exit velocity of the air from the swirler. The results were compared with those of Raj and Ganesan [29]. Moreover, the effect of auxiliary primary holes (APH) on the liner to CRZ creation was also studied. From the results of studies by Li et al. [15] and Chowdhury and Noma [17], it was indicated that by increasing the air stream in order to interrupt the stream from the blade swirler, a large and intense CRZ can be created. Furthermore, it can reduce the air recirculation in death zone (the edge of the chamber). For this reason, the quantity of air was increased into liner with the drilling of the diffuser. The expected results were to increase the interruption of the air stream which can lead to an increase in CRZ intensity and reduction in the temperature of the wall liner. The details of the design geometry are shown in Table 3.

Table 2. Relative of air fraction into each section to flue gas temperature.

\begin{tabular}{cccccc}
\hline Flue gas & Mass flow & \multicolumn{4}{c}{ Actual air fraction into each section $(\%)$} \\
\cline { 3 - 6 } temp $\left({ }^{\circ} \mathrm{K}\right)$ & of fuel $(\mathrm{g} / \mathrm{s})$ & Liner & Primary & Secondary & Dilute \\
\hline 1100 & 0.292 & 14.18 & 7.09 & 31.20 & 47.53 \\
1200 & 0.334 & 16.22 & 8.11 & 35.67 & 40.00 \\
1300 & 0.377 & 18.29 & 9.15 & 40.24 & 32.32 \\
1400 & 0.420 & 20.41 & 10.20 & 44.90 & 24.49 \\
1500 & 0.465 & 22.56 & 11.28 & 49.62 & 16.54 \\
\hline
\end{tabular}

Table 3. Geometry of can combustor for computation.

\begin{tabular}{lcccccccccccc}
\hline \multicolumn{1}{c}{ Various } & \multicolumn{10}{c}{ Combustion model } \\
\cline { 2 - 13 } \multicolumn{1}{c}{ geometry } & 1 & 2 & 3 & 4 & 5 & 6 & 7 & 8 & 9 & 10 & 11 & 12 \\
\hline SA & 60 & 60 & 60 & 60 & 45 & 45 & 45 & 45 & 30 & 30 & 30 & 30 \\
HTR & 0.3 & 0.3 & 0.6 & 0.6 & 0.3 & 0.3 & 0.6 & 0.6 & 0.3 & 0.3 & 0.6 & 0.6 \\
APH & Yes & No & Yes & No & Yes & No & Yes & No & Yes & No & Yes & No \\
\hline
\end{tabular}

\section{Computational detail}

Physical mesh: the unstructured mesh of the can combustor geometry was created by using GAMBIT package of the ANSYS-FLUENT 15.0.7 Software pre-processing to discrete the computational domain. The mesh is generated by an automated method due 
to the complicated geometry of the combustion chamber. Non-uniform tetrahedral cells were implemented in all of the case studies of the can combustor. A very fine grid density was employed in the swirler and in the holes of the liner region. A very coarse grid was applied to the outlet region.

Boundary conditions: The following are the boundary conditions were used:

- Inlet: The inlet boundary involved mass flow rate along with turbulence intensity and hydraulic diameter. An air mass flow rate of $0.0157 \mathrm{~kg} / \mathrm{s}$, turbulence intensity of $1 \%$, and hydraulic diameter of $102.30 \mathrm{~mm}$ were specified at the inlet.

- Outlet: The outlet was applied to atmospheric pressure.

- Wall: Wall boundary conditions were enforced on all faces. Adiabatic and no-slip boundary conditions were applied at the walls.

- Interior: The interior boundary condition was specified at the interface of the volume mentioned in 3.3.1.

- Fluid: The boundary condition of the fluid was applied to all of the volume geometry.

Computational modeling: The CFD code ANSYS-FLUENT 15.0.7 Software was used in order to solve the discretized governing equation. As mentioned above, the standard $\mathrm{k}-\varepsilon$ model of turbulence has been employed in this work due to a lower inlet Reynolds number. Reynolds number did not vary with the temperature condition due to the assumption of isothermal flow; for this reason, as well as the results from an expansive literature review, the $\mathrm{k}-\varepsilon$ model, was chosen to solve the non-isentropic character of turbulent flow. Furthermore, the k- $\varepsilon$ model was also used for economical reasons. In all of the simulations, a steady-state pressure- based solver were used to solve the governing equations because the air was assumed to be an incompressible fluid and the mass flow rate of air was constant. The Semi Implicit Method for Pressure- Linked Equations (SIMPLE) algorithm was used for the iteration technique of pressure-velocity coupling. In order to enhance the solution accuracy, the Quadratic Upstream Interpolation for Convective Kinetics (QUICK) scheme was implemented for the discretization of the convective terms [5].

\section{RESULT AND DISCUSSIONS}

\section{Effect of snout angle}

In this modeling study, the analytical effect of the snout angle to CRZ showed that the air fraction into swirler decreased due to a decrease in the snout angle, while in contrast, the amount of stream flowing into the outer liner to serve the primary, secondary, and dilute zones was increased. The intensity of CRZ was generated by influencing the following: 1) the flow behind the blade swirler and 2) the air fraction into the primary holes, secondary holes, and dilute holes of the liner [11,12]. The stream flowing from the outer liner was not sufficient enough to interrupt the stream from the swirler. The results of the stream interruption between the swirler stream and the outer liner stream can be considered from the re-circulating velocity contour which was shown in Figure 3 . The re-circulating velocity was indicated as a re-circulating velocity with a ratio of radial position per axial inlet velocity. A large amount of discretized velocity was indicated with a negative value of the axial per inlet velocity ratio.

As shown in Figure 3, it was discovered that when the snout angle was decreased, the quantity of air coming into outer liner was increased which affected an increase of 
the air fraction into the primary zone. At the same time, the air fraction into the swirler decreased, but it was sufficient to generate an interruption of exit velocity of the air between the swirler and the holes of the liner. The stream velocity was more intense in the primary zone which was considered in Model 1, Model 5, and in Model 9. The ratio of the axial along radial position per inlet velocity of Model 9 was found to be higher than in Model 1 and in Model 5 because the re-circulating velocity of Model 9 is higher than in Model 1 and Model 5. In addition, the created turbulent swirling vortex is greater than the other models which contributed to the actual combustion in the system.

From Figure 4, the validation of the axial along radial position per inlet velocity on CRZ intensity can be indicated from the large negative value of the axial per inlet velocity ratio. The validation in this work was compared with the results of Raj and Ganesan [29] in which the swirler design was similar to the swirler used in this research. The results found that the axial per inlet velocity ratio of the length and the radius of combustor were closely aligned with the results of them, which can be seen as the polynomial curve in Figure 4. Furthermore, it was found that the axial per inlet velocity ratio from Models 1, 5, and 9 had higher a value than the results of Raj and Ganesan. This can be explained in that a large CRZ intensity was generated from the effect of holes in the primary, secondary, and dilute zones. The effect of holes in the liner created an increase in the flow stream from outer liner, and this flow interrupted the main stream from the swirler. For this reason, a CRZ of great intensity was generated.

Figure 5 shows the validation of axial per inlet velocity on the centerline. The results found that the ratio of axial per inlet velocity on the centerline of Models 1, 5, and 9 were close to results found in a study by Eldrainy et al. [13,14]. For all of the results, the combustion in the primary zone was very intense. From the results of Model 9 , it was found that a negative value of the axial per inlet velocity ratio was more than that of any other model due to the influence of the snout angle of Model 9 which generated an intense of CRZ as compared to other models. In addition to taking the pressure drop by various snout angles into consideration, the following was discovered: 1) an increase in the angle of the snout will cause a lower stream in the outer liner, and 2) it will also cause a high pressure drop in the can chamber.

The dimensionless pressure drop in the can combustor can be described with Pressure Loss Factor (PLF), which is expressed in equation (2) [5]. Table 4 shows swirling number $\left(S_{n}\right)$ and PLF from the snout angle effect.

$$
P L F=\frac{P_{1}-P_{2}}{\frac{1}{2} \rho U_{o}^{2}}
$$

In which, the inlet stagnation pressure $\left(P_{1}\right)$ is measured in the inlet pipe upstream and exit stagnation pressure $\left(P_{2}\right)$ is obtained in the end of pipe, $\rho$ and $U_{o}$ are the density of the fluid and the inlet velocity of the pipe, respectively.

\section{Effect of hub to tip ratio}

This work examined the influence of the hub to tip ratio on CRZ and PLF. The objective of this topic was to uncover the effects of the volumetric flow rate and velocity of air that arises from the swirler. The hub to tip ratio of the swirler was varied at 0.33 and 0.67 . The results of this study found that the hub to tip ratio of 0.33 is more suitable than that of 0.67. This result is similar to the work of Raj and Ganesan [29]. The results of the study of stream modeling behavior of air into the can combustor showed that when the hub to tip ratio was increased, the stream flow rate of air into the swirler was reduced, but the stream velocity increased. 
This computation was carried out in order to discover which parameter, the volumetric flow rate or the exit velocity of air from swirler, could create a greater intensity of CRZ. The results found that CRZ decreased when the hub to tip ratio was increased. This decrease was caused by a lower volumetric flow rate of air from the blade swirler. The flow rate had a greater effect upon generating the CRZ than the exit velocity of air from swirler. In all of the examined cases, the results found that the ratio of axial per inlet velocity in the hub to tip ratio of 0.33 are higher than the ratio of 0.67 in the primary zone. Furthermore, a high value of the hub to tip ratio increased a high pressure drop in the diffuser zone which increased the PLF.

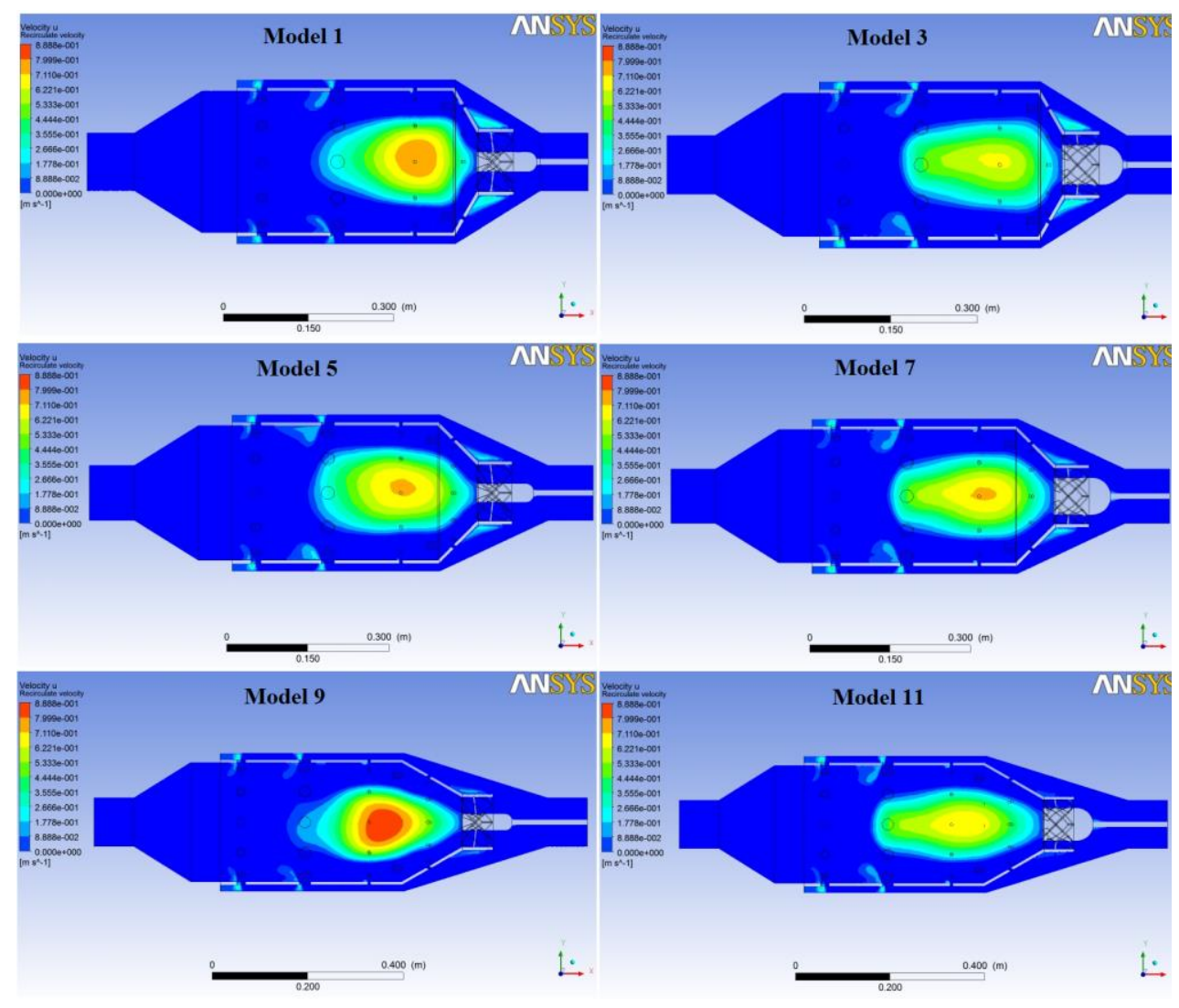

Figure 3 . The re-circulating velocity contour of combustor with auxiliary primary holes

The region with reverse velocity is termed as CRZ, which is mainly responsible for frame stabilization. As far as the residence time for the reactant species and the heat transfer rate are concerned, this recirculation zone is critical. In turn, the above parameters depend on the volume and surface area of the CRZ.

\section{Effect of auxiliary primary holes}

From the computation, the effect, that the auxiliary primary holes had on the behavior of the air flow inside the can combustor. This study was aimed to discover the effect that the auxiliary holes in the diffuser of the liner actually had on CRZ generation. Having auxiliary holes was expected to increase the interruption of air between the air stream and the air originating from the blade swirler, which was expected to create a greater intensity of CRZ and reduce the temperature of liner wall. In all examined cases, the combustor with auxiliary primary holes increased the air into the primary zone which was able to generate a higher CRZ and higher swirling turbulence than the combustor 
without the auxiliary primary holes. These results were in accordance with the results of Li et al. [15] and Chowdhury and Noman [17]. Furthermore, the advantage of the auxiliary primary holes was to reduce the pressure drop on the diffuser zone which would decrease the PLF and increase the swirling number.

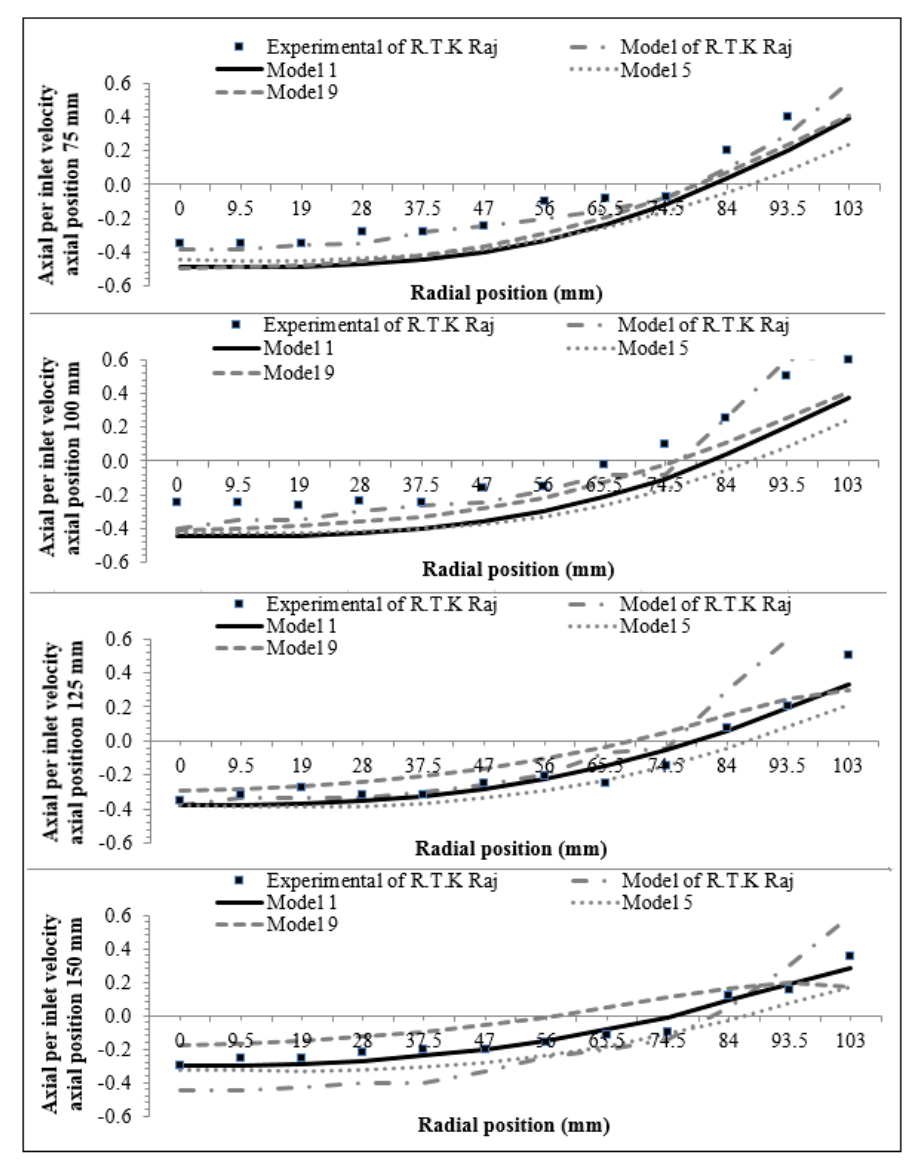

Figure 4. Validation of velocity profile.

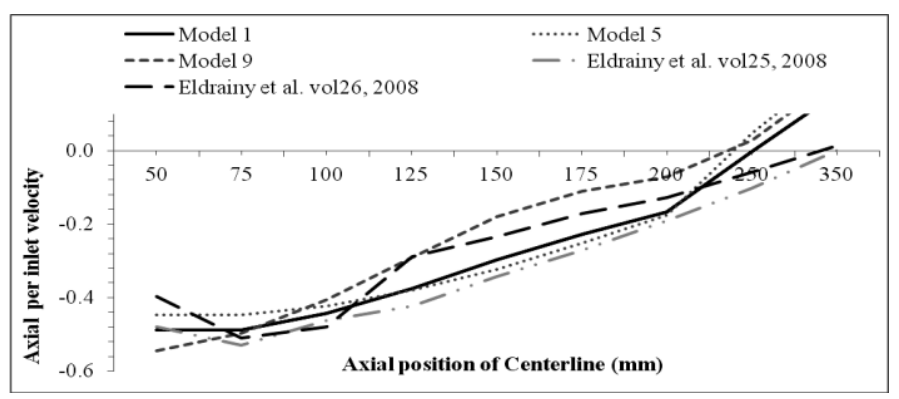

Figure 5. Validation of axial per inlet velocity at centerline.

Table 4. Swirling number and PLF for all cases of can combustor.

\begin{tabular}{lcccccccccccc}
\hline & \multicolumn{11}{c}{ Combustion model } \\
\cline { 2 - 13 } & 1 & 2 & 3 & 4 & 5 & 6 & 7 & 8 & 9 & 10 & 11 & 12 \\
\hline $\mathrm{S}_{\mathrm{n}}$ & 1.38 & 0.73 & 0.85 & 0.59 & 1.23 & 0.62 & 0.96 & 0.86 & 1.52 & 0.81 & 0.89 & 0.84 \\
PLF & 2.71 & 5.53 & 3.32 & 3.38 & 2.44 & 2.53 & 2.98 & 3.03 & 2.28 & 2.36 & 2.76 & 2.75 \\
\hline
\end{tabular}




\section{The optimal condition for combustion geometry}

By using multiple regression analysis, the optimal conditions for combustion geometry were studied. The Quadratic Response Model was used to solve swirling number in this case with auxiliary primary holes $\left(\mathrm{y}_{1}\right)$ and without auxiliary primary holes $\left(\mathrm{y}_{2}\right)$ which is expressed in equations (3) and (4), respectively.

$$
\begin{aligned}
& y_{1}=2.4724-0.0339 x_{1}-0.6482 x_{2}+0.0003 x_{1}^{2}-1.1949 x_{2}^{2}+0.0098 x_{1} x_{2} \\
& y_{2}=0.6523+0.0018 x_{1}+0.5108 x_{2}+0.0001 x_{1}^{2}+0.3666 x_{2}^{2}-0.0167 x_{1} x_{2}
\end{aligned}
$$

The optimal quadratic response surface results are shown in Figure 6. From the results of the optimal design with the auxiliary primary holes, an optimal design was found to have a snout angle of $30^{\circ}$ and hub to tip ratio of 0.33 which generated a swirling number of 1.48 . This result matched the CFD calculation. The percentage error of the swirling number between equation (1) and the quadratic response model was $2.63 \%$. With respect to the results of the optimal design without auxiliary primary holes, it was found that an optimal design had a snout angle of $30^{\circ}$ and hub to tip ratio of 0.67 . Moreover, this design had a swirling number of 0.88 , and a percentage error of $4.54 \%$.

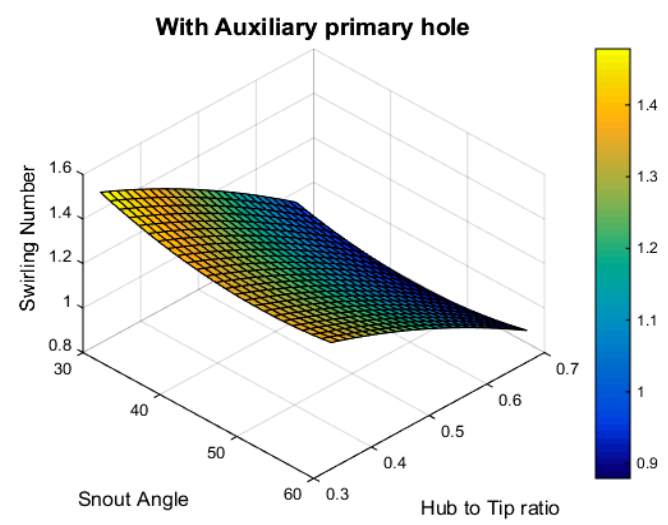

(a)

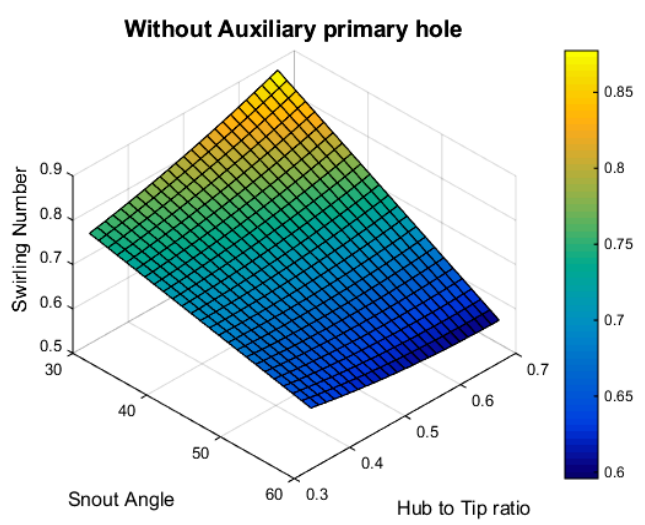

(b)

Figure 6. Response surface results for swirling number (a) with auxiliary primary holes and (b) without auxiliary primary holes.

\section{CONCLUSION}

This work presents a study of flow behaviors and the effects of various inlet geometry designs on swirling flow in a can combustor. The computational study was carried out by using CFD method compared with literature review. The ability to create the CRZ was indicated by the swirl number and the PLF. In order to determine the CRZ and PLF, the snout angle, hub to tip ratio of the vane swirler, and influence of auxiliary primary holes on liner were studied in this work. Using the CFD model, it was found that a lower snout angle and a lower hub to tip ratio can create greater swirling turbulence than a higher snout angle and higher hub to tip ratio. The obtained results were close to those found in a review of the literature. The optimal design consisted of a $30^{\circ}$ snout angle, a 0.33 of hub to tip ratio and had auxiliary primary holes, which generated the maximum swirling number of 1.52 and the lowest PLF value of 2.28. This designed combustor was suitable as a heat generating device. Simple construction, inexpensive and good swirling flow are some advantages of using this combustor design. 


\section{ACKNOWLEDGEMENTS}

This work has received scholarship under the Post-Doctoral Training Program from Research Affairs and Graduate School, Khon Kaen University, Thailand. (Grant no. 59261). Moreover, the authors would like to thank Farm Engineering and Automation Technology (FEAT) Research Group, Khon Kaen University for technical support

\section{REFERENCES}

[1] Cohen H, Rogers GFC and Saravanamuttoo HIH. Gas turbine theory. Longman house. (1996).

[2] Ibrahim TK and Rahman MM. Effects of isentropic efficiency and enhancing strategies on gas turbine performance. Journal of Mechanical Engineering and Sciences. 2013;4;383-396.

[3] Rolls-Royce plc. The jet engine. Renault printing. (1996).

[4] Lefebvre AH. Gas turbine combustion. Hemisphere publishing corporation. (1983).

[5] Eldrainy YA, Saqr KM, Aly HS and Jaafar MNM. CFD insight of the flow dynamics in a novel swirler for gas turbine combustors. International Communications in Heat and Mass Transfer. 2009;36;936-941.

[6] Syred N and Beer JM. Combustion in swirling flows: A review. Combustion and Flame. 1974;23;143-201.

[7] Xia JL, Smith BL, Benim AC, Schmidli J and Yadigaroglu G. Effect of inlet and outlet boundary conditions on swirler flows. Computer and Fluids. 1997;26;811823.

[8] Dang XX, Zhao JX and Ji HH. Experimental study of effects of geometric parameters on combustion performance of dual-stage swirler combustor. Journal of Aerospace and Power. 2007;22;1639-1645.

[9] Hamada KI, Rahman MM, Ramasamy D. Noor MM and Kadirgama K. Numerical investigation of in-cylinder flow characteristics of hydrogen-fuelled internal combustion engine. Journal of Mechanical Engineering and Sciences. 2016;10;1792-1802.

[10] Reda E, Zulkifli R and Harun Z. Large eddy simulation of wind flow through an urban environment in its full-scale wind tunnel models. Journal of Mechanical Engineering and Sciences. 2017;11;2665-2678.

[11] Singh SN, Seshadri V, Singh RK and Mishra T. Flow characteristics of an annular gas turbine combustor model for reacting flows using CFD. Journal of Scientific and Industrial Research. 2006;65;921-934.

[12] Grech N, Mehdi A, Zachos PK, Pachidis V and Singh R. Effect of combustion geometry on performance of airblast atomizer under sub-atmospheric conditions. Engineering Application of Computational Fluid Mechanics. 2012;2;203-213.

[13] Eldrainy YA, Ridzwan JJM and Jaafar MNM. Prediction of the flow inside a micro gas turbine combustor. Jurnal Mekanikal. 2008;25;50-63.

[14] Eldrainy YA, Jaafar MNM and Lazim TM. Numerical investigation of the flow inside primary zone of turbular combustor model. Jurnal Mekanikal. 2008;26;162-176.

[15] Li Y, Li R, Li D, Bao J and Zhang P. Combustion charecteristic of a slotted swirler combustion: An experimental test and numerical validation. International Communications in Heat and Mass Transfer. 2015;66;140-147. 
[16] Pathan FH, Patel NK and Tadvi MV. Numerical investigation of the combustion of methane air mixture in gas turbine can-type combustion chamber. International Journal of Scientific and Engineering Research. 2012;3;1-7.

[17] Chowdhury SJ and Noman MS. Effect of cooling air on swirler combustor. Journal of Mechanical Engineering. 2007;37;1-9.

[18] Green AS and Whitelaw JH. Isothermal models of gas turbine combustor. Journal of Fluid Mechanics. 1983;126;399-412.

[19] Lilley DG. Flow modeling in practical combustors: A review, Journal of Energy. 1979;3;193.

[20] Gupta AK, Lilley DG and Syred N. Swirl Flows. Abacus press. (1984).

[21] Sloan DG, Smith PJ and Smoot LD. Modeling of swirl in turbulence flow system. Progress in Energy and Combustion Science. 1986;12;163.

[22] Khandelwal B, Lili D and Sethi V. Design and study on performance of axial swirler for annular combustor by changing different design. Journal of Energy Instutite. 2014;87;372-382.

[23] Vondal $\mathbf{J}$ and Hajek $\mathbf{J}$. Swirler flow prediction in model combustor with axial guide vane swirler. Chemical Engineering Transactions. 2012;29;1069-1074.

[24] Shih LH, Koseff JR, Ivey GN and Ferziger JH. Parameterization of turbulent fluxes and scales using homogeneous sheared stably- stratified turbulence simulations. Journal of Fluid Mechanics. 2005;525;193-214.

[25] Muthakumar $\mathrm{P}$ and Balakrishnan SR. CFD analysis of recirculating flows induced by axial swirler. International Journal of Engineering Research and Technology. 2013;2;86-90.

[26] Fu Y, Jeng SM and Tacina R. Characteristics of the swirler flow generated by an axial swirler. International Conference on ASME Turbo Expo. Nevada, USA. 2005 .

[27] Dhakiya AK, Shah BK and Mohite AS. Study of flow through combustion swirler with the effect of duffuser on the recirculation zone. International Journal of Engineering Research and Development. 2012;3;68-73.

[28] Jaafar MNM, Osman KJMS and Ishak MSA. Combustion Aerodynamic using radial swirler. International Journal of the Physical Science. 2011;6;3091-3098.

[29] Raj RTK and Ganesan V. Study on the effect of various parameters on flow development behind vane swirlers. International Journal of Thermal Sciences. 2008;47;1204-1225.

[30] Kumari M and Jagruti S. Experimental analysis of flow through rotating swirler in combustion chamber. International Journal of Science, Engineering and Technology Research. 2014;3;2105-2109.

[31] Kumari M. CFD analysis of flow through rotating combustion swirler. Journal of Computer Science and Engineering and Technology. 2014;5;820-823.

[32] Shah BK, Dhakiya AK and Mohite AS. Experimental study on the effect of various parameters of recirculating flows induced by vane swirler. International Journal of Educational Research and Technology. 2012;3;24-31.

[33] Mattingly JD. Element of Gas Turbine Propulsion. McGraw-Hill Inc. (1996).

[34] Walsh PP and Fletcher P. Gas Turbine Performance. Blackwell science. (2004).

[35] Yakhot A and Orszag S. Renormalisation group analysis of turbulence: I, Basic theory. Journal of Scientific Computing. 1986;1;3-51. 